\title{
Usefulness of preoperative estimated glomerular filtration rate to predict complications after curative gastrectomy in patients with clinical T2-4 gastric cancer
}

\author{
Yuri Tanaka $^{1} \cdot$ Mitsuro Kanda $^{1} \cdot$ Chie Tanaka $^{1} \cdot$ Daisuke Kobayashi $^{1} \cdot$ \\ Akira Mizuno $^{1}$ - Naoki Iwata ${ }^{1} \cdot$ Masamichi Hayashi $^{1} \cdot$ Yukiko Niwa $^{1}$. \\ Hideki Takami $^{1}$ - Suguru Yamada ${ }^{1}$ ' Tsutomu Fujii $^{1}$ - Goro Nakayama ${ }^{1}$. \\ Hiroyuki Sugimoto $^{1} \cdot$ Michitaka Fujiwara $^{1} \cdot$ Yasuhiro Kodera $^{1}$
}

Received: 2 August 2016/Accepted: 2 October 2016/Published online: 12 October 2016

(c) The International Gastric Cancer Association and The Japanese Gastric Cancer Association 2016

\begin{abstract}
Background Gastrectomy with systemic lymphadenectomy is the standard of care for resectable gastric cancer (GC), but it is sometimes associated with postoperative morbidity. Predicting complications is therefore an essential part of risk management in clinical practice. The renal function is routinely evaluated before surgery by blood examinations to determine dose of medication and infusion. However, the value of various parameters of renal function in prediction of postoperative complications remain unclear.

Methods We included 315 patients who underwent curative D2 gastrectomy for clinical T2-T4 GC without preoperative treatment, and evaluated the correlation between the incidence of postoperative complications and the indicators of renal function.

Results Forty-three patients experienced clinically relevant postoperative complications. Estimated glomerular filtration rate (eGFR) showed a higher area under the curve for predicting complications compared with urea nitrogen, creatinine, and creatinine clearance. The optimal eGFR cutoff value was $63.2 \mathrm{ml} / \mathrm{min} / 1.73 \mathrm{~m}^{2}$, and eGFR $<63.2$ was an independent risk factor for postoperative complications in multivariable analysis (odds ratio 4.67; $95 \%$ confidence interval 2.16-10.5; $p<0.001)$. Particularly, the incidence of anastomotic leakage was significantly higher in patients with eGFR $<63.2$ than those with eGFR $\geq 63.2(9.4 \%$ vs. $3.5 \%)$. eGFR $<63.2$ was also
\end{abstract}

Yasuhiro Kodera

ykodera@med.nagoya-u.ac.jp

1 Department of Gastroenterological Surgery (Surgery II), Nagoya University Graduate School of Medicine, 65 Tsurumai-cho, Showa-ku, Nagoya 466-8550, Japan associated with a higher incidence of postoperative complications independent of age, body mass index, operative procedure, and clinical disease stage. Postoperative hospital stay was significantly longer in the eGFR $<63.2$ group. Conclusions Preoperative eGFR is a simple and useful predictor for complications after gastrectomy in patients with GC and may improve clinical care and the process of obtaining informed consent.

Keywords Gastric cancer - Estimated glomerular filtration rate $\cdot$ Postoperative complication · Gastrectomy

\section{Introduction}

Gastric cancer (GC) is a common malignant tumor of the gastrointestinal tract and is considered a major public health threat worldwide [1-3]. Gastrectomy with systemic lymphadenectomy is an important factor in the treatment of this disease [4, 5]. Despite technical advances and improvements in perioperative care, the procedure carries high morbidity and a protracted recovery period, and surgeons are now legally bound to inform patients of the potential risks involved with treatment $[6,7]$. Essential to the decision-making process before surgery is identification of those patients most at risk of developing a serious complication. Therefore, developing a prediction tool based exclusively on preoperatively determined factors is warranted, and an ideal model to predict complications in surgical patients should be simple, have minimal cost burden, and be readily applicable to all patients and hospitals [8].

Several parameters such as body mass index (BMI), C-reactive protein, albumin, prognostic nutrition index, and Glasgow prognostic score have been reported as predictive 
factors for complications after gastrectomy, but their clinical utility remains controversial [9-12]. Although integrated scoring systems such as POSSUM, APACHE II score, and the comprehensive geriatric assessment arguably possess greater predictive performance compared with single parameters, these scoring systems are unlikely to become routine assessment tools in clinical practice because they are highly labor intensive [13]. Evaluation of renal function is included in a routine preoperative screening to determine the optimal dose of medication and infusion. Serum creatinine $(\mathrm{Cr})$, urea nitrogen, creatinine clearance $(\mathrm{CCr})$, and estimated glomerular filtration rate (eGFR) are convenient indices to determine the renal function [14]. Hayashi et al. reported that low baseline $\mathrm{CCr}$ was significantly associated with postoperative complications in patients who underwent neoadjuvant S-1 plus cisplatin followed by D2 gastrectomy [15]. However, to our knowledge there have been no studies comparing the usefulness of preoperative levels of renal function indicators for predicting postoperative complications following digestive surgery in patients without prior treatments.

Our aim was to evaluate the predictive value of renal function indicators, simple parameters based on data from routine laboratory tests, for morbidity after gastrectomy and to propose the optimal cutoff value.

\section{Patients and methods}

\section{Ethics}

This study conforms to the ethical guidelines of the World Medical Association Declaration of Helsinki-Ethical Principles for Medical Research Involving Human Subjects, and written informed consent for surgery and the use of clinical data was obtained from all patients as required by the Institutional Review Board of Nagoya University [16].

\section{Patient inclusion}

Between January 1999 and May 2016, 1098 patients underwent gastrectomy for GC at the Department of Gastroenterological Surgery, Nagoya University. Of these, we retrospectively selected 315 patients for analysis according to the following inclusion criteria: no preoperative treatment, R0 gastrectomy performed, D2 gastrectomy performed according to the Japanese Gastric Cancer Treatment Guidelines [17], clinical T2-T4 (advanced) GC according to the TNM Classification of Malignant Tumours, 7th Edition [18], and sufficient data for analysis (Fig. 1).

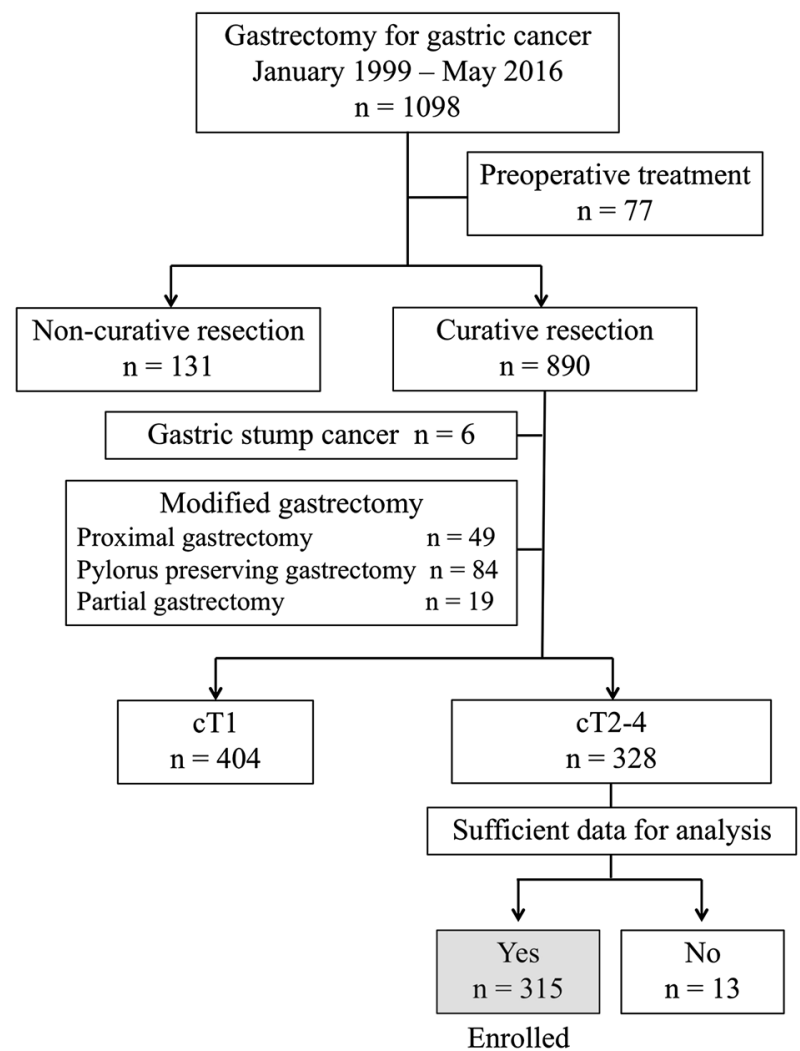

Fig. 1 Flowchart of patient enrollment

\section{Perioperative treatment}

Gastrectomy with D2 or further lymphadenectomy was performed according to the Japanese Gastric Cancer Treatment Guidelines [17], and the choice of the reconstruction method was at the surgeon's discretion. A first-generation cephem-based antibiotic was administered immediately before surgery and every $3 \mathrm{~h}$ during surgery [19]. Oral intake was routinely started on postoperative day 1 , if patients had no obvious problems. Percutaneous drainage or the replacement of drainage tubes was performed when signs of inadequate drainage were found by computed tomography scan or ultrasound [20]. Clinically relevant postoperative complications were defined as grade III or IV complications according to the Clavien-Dindo classification [21].

\section{Evaluation of the predictive value of preoperative renal function indicators}

Blood examinations were conducted routinely 2 days before surgery. eGFR was calculated as follows for males: $\operatorname{eGFR}\left(\mathrm{ml} / \mathrm{min} / 1.73 \mathrm{~m}^{2}\right)=194 \times \mathrm{Cr}^{-1.094} \times \mathrm{age}^{-0.287}$, and for females: $\quad \mathrm{eGFR}\left(\mathrm{ml} / \mathrm{min} / 1.73 \mathrm{~m}^{2}\right)=194 \times \mathrm{Cr}^{-1.094} \times$ age $^{-0.287} \times 0.739$. To compare with eGFR, the predictive value of $\mathrm{CCr}$ was determined using the Cockroft-Gault 
method as follows for males: [(140-age $) \times$ body weight $(\mathrm{kg})] /(72 \times \mathrm{Cr})$, and for females: [(140age $\times$ body weight $(\mathrm{kg}) \times 0.85] /(72 \times \mathrm{Cr})$ [14]. We also evaluated the correlations between the incidence of clinically relevant postoperative complications and potential predictive factors and performed a subgroup analysis in which the patients were stratified according to age, BMI, type of gastrectomy, and clinical disease stage.

\section{Statistical analysis}

The sensitivity and specificity of the nominated variables to predict postoperative complications were assessed using a receiver operating characteristic curve analysis [22]. Goodness-of-fit was assessed by calculating the area under the curve (AUC), and the optimal cutoff value was determined using the Youden index [23]. The qualitative $\chi^{2}$ test and quantitative Mann-Whitney test were used to compare the two groups. Multivariable analysis to identify independent risk factors for postoperative complications was performed using binomial logistic analysis, including variables with $p<0.1$ as covariates in the final model. All statistical analyses were performed using JMP 10 software (SAS Institute, Cary, NC, USA). A statistically significant difference was indicated by a $p$ value $<0.05$.

\section{Results}

\section{Patient characteristics}

The baseline clinical characteristics of the 315 patients are summarized in Table 1. Median age was 66 years, and male-to female ratio was 234:81. Regarding clinical tumor depth (cT), 143, 104, and 68 patients were classified as cT2, cT3, and cT4, respectively, and 91, 74, 68, 59, 16, and 7 patients were classified as clinical TNM stages IB, IIA, IIB, IIIA, IIIB, and IIIC, respectively. The mean eGFR was $74.1 \mathrm{ml} / \mathrm{min} / 1.73 \mathrm{~m}^{2}$.

\section{Predictive value of eGFR and its relevant parameters}

Forty-three patients (13.7\%) had grade III or IV postoperative complications. The AUC value indicating power to predict postoperative complications was 0.597 for urea nitrogen, 0.656 for $\mathrm{Cr}, 0.630$ for $\mathrm{CCr}$, and 0.661 for eGFR. Thus, eGFR was found to have the best predictive power among various indicators of renal function. The optimal cutoff value for predicting complications with eGFR was $63.2 \mathrm{ml} / \mathrm{min} /$ $1.73 \mathrm{~m}^{2}$ (sensitivity $=53 \%$, specificity $=78 \%$ ) (Fig. $\left.2 \mathrm{a}\right)$. Compared with the eGFR $\geq 63.2$ group, patients in the eGFR $<63.2$ group were associated with older age, higher
Table 1 Demographics and preoperative clinical characteristics of 315 patients

\begin{tabular}{|c|c|}
\hline Variables & Number of patients \\
\hline Age, median (range) (years) & $66(20-96)$ \\
\hline \multicolumn{2}{|l|}{ Sex } \\
\hline Male & 234 \\
\hline Female & 81 \\
\hline \multicolumn{2}{|l|}{ Diabetes mellitus } \\
\hline Absent & 276 \\
\hline Present & 39 \\
\hline \multicolumn{2}{|l|}{ Cardiac comorbidity } \\
\hline Absent & 225 \\
\hline Present & 90 \\
\hline \multicolumn{2}{|l|}{ Pulmonary comorbidity } \\
\hline Absent & 297 \\
\hline Present & 18 \\
\hline \multicolumn{2}{|l|}{ Renal comorbidity } \\
\hline Absent & 310 \\
\hline Present & 5 \\
\hline \multicolumn{2}{|l|}{ Preoperative symptom } \\
\hline Absent & 167 \\
\hline Present & 148 \\
\hline Preoperative body mass index, mean \pm SD & $22.0 \pm 3.3$ \\
\hline Preoperative eGFR $\left(\mathrm{ml} / \mathrm{min} / 1.73 \mathrm{~m}^{2}\right)$, mean $\pm \mathrm{SD}$ & $74.1 \pm 17.6$ \\
\hline \multicolumn{2}{|l|}{ Tumor location } \\
\hline Entire & 10 \\
\hline Upper third & 70 \\
\hline Middle third & 117 \\
\hline Lower third & 118 \\
\hline \multicolumn{2}{|l|}{ Tumor size $(\mathrm{mm})$} \\
\hline$<50$ & 174 \\
\hline$\geq 50$ & 141 \\
\hline \multicolumn{2}{|l|}{ UICC cT factor } \\
\hline $\mathrm{cT} 1$ & 0 \\
\hline $\mathrm{cT} 2$ & 143 \\
\hline cT3 & 104 \\
\hline $\mathrm{cT} 4$ & 68 \\
\hline \multicolumn{2}{|l|}{ UICC $\mathrm{cN}$ factor } \\
\hline $\mathrm{cNO}$ & 152 \\
\hline $\mathrm{cN} 1$ & 92 \\
\hline $\mathrm{cN} 2$ & 59 \\
\hline $\mathrm{cN} 3$ & 12 \\
\hline \multicolumn{2}{|l|}{ UICC clinical stage } \\
\hline IB & 91 \\
\hline IIA & 74 \\
\hline IIB & 68 \\
\hline IIIA & 59 \\
\hline IIIB & 16 \\
\hline IIIC & 7 \\
\hline
\end{tabular}

$\overline{S D \text { standard deviation, UICC Union for International Cancer Control }}$ 
Fig. 2 a Predictive values of urea nitrogen, creatinine, creatinine clearance, and estimated glomerular filtration rate (eGFR) for postoperative complications evaluated by a receiver operating characteristic curve analysis. b Comparison of the number of postoperative hospital days between the two groups according to preoperative eGFR
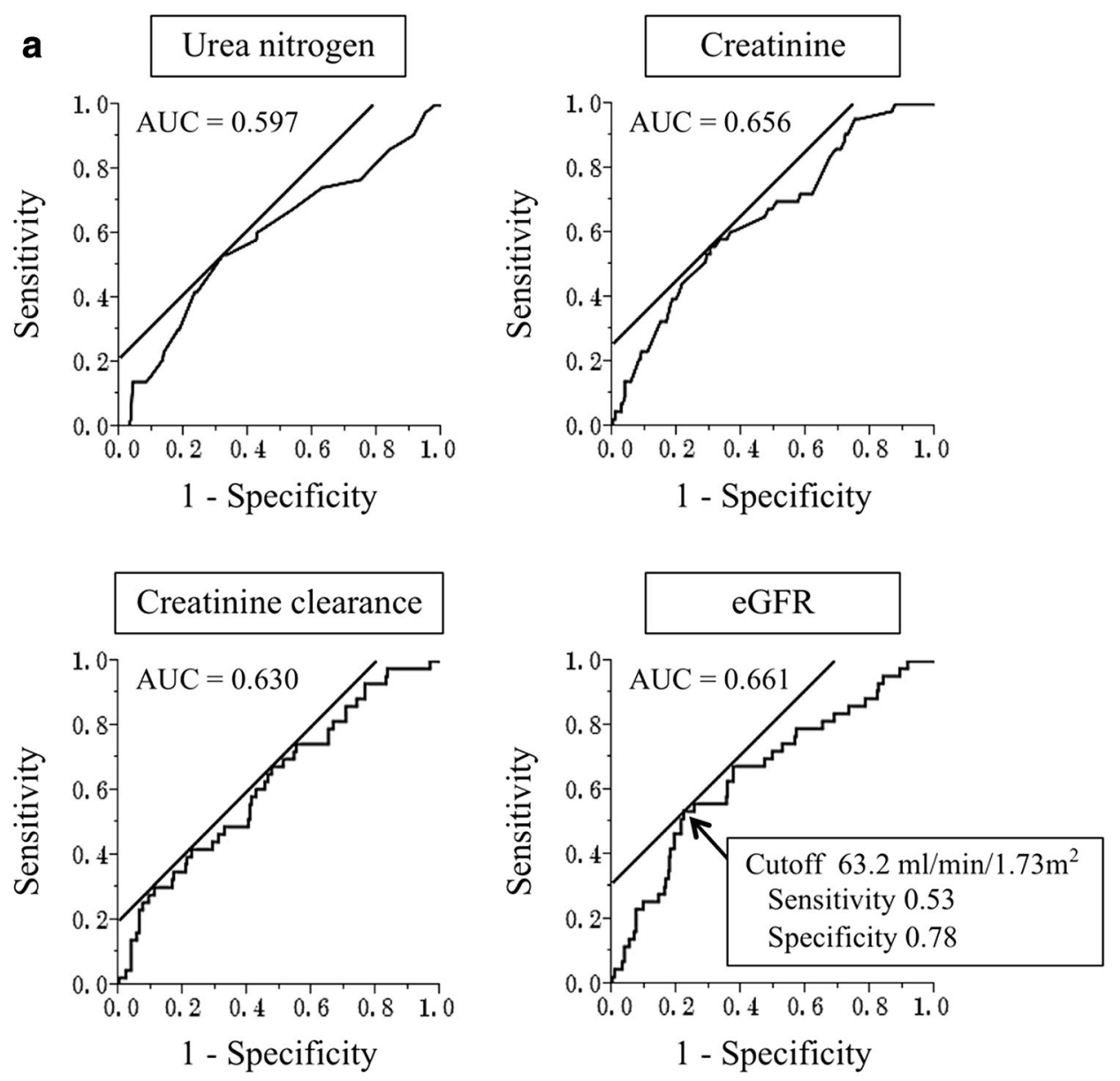

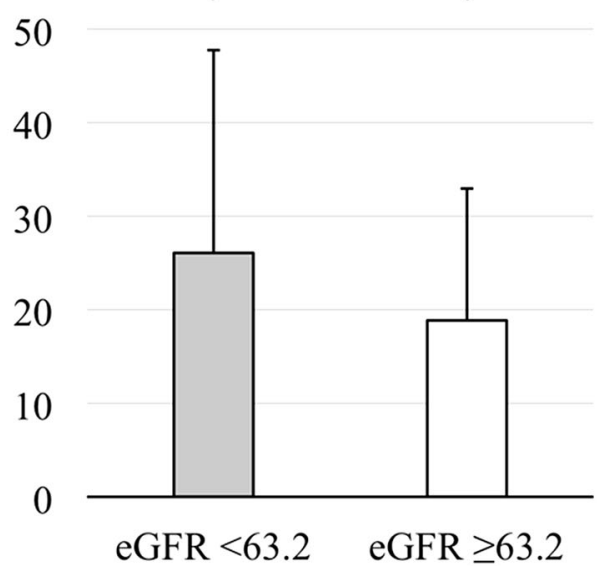

prevalence of cardiovascular and renal comorbidities, and more frequent postoperative complications (Table 2). In contrast, there were no significant differences in preoperative BMI, macroscopic tumor size, cT stage, clinical N stage, or clinical disease stage, type of gastrectomy, operative time, blood loss, and number of dissected lymph nodes between the two groups (Table 2). Postoperative hospital stay was significantly longer in the eGFR $<63.2$ group than in the eGFR $\geq 63.2$ group (Fig. 2b). With respect to the types of complications, the cumulative number of patients who experienced anastomotic leakage, leakage of pancreatic fluids, intraabdominal abscess, bowel obstruction, cardiopulmonary 
Table 2 Comparison between two subgroups according to preoperative estimated glomerular filtration rate (eGFR)

\begin{tabular}{|c|c|c|c|}
\hline Variables & $\begin{array}{l}\text { eGFR }<63.2 \\
(n=85)\end{array}$ & $\begin{array}{l}\mathrm{eGFR} \geq 63.2 \\
(n=230)\end{array}$ & $p$ value \\
\hline $\begin{array}{l}\text { Age, median (range) } \\
\text { (years) }\end{array}$ & $72(43-96)$ & $64(20-90)$ & $<0.001$ \\
\hline \multicolumn{4}{|l|}{ Sex } \\
\hline Male & 69 & 165 & \multirow[t]{2}{*}{0.082} \\
\hline Female & 16 & 65 & \\
\hline \multicolumn{4}{|l|}{ Diabetes mellitus } \\
\hline Absent & 71 & 205 & \multirow[t]{2}{*}{0.191} \\
\hline Present & 14 & 25 & \\
\hline \multicolumn{4}{|l|}{ Cardiac comorbidity } \\
\hline Absent & 48 & 177 & \multirow[t]{2}{*}{$<0.001$} \\
\hline Present & 37 & 53 & \\
\hline \multicolumn{4}{|l|}{ Pulmonary comorbidity } \\
\hline Absent & 81 & 216 & \multirow[t]{2}{*}{0.633} \\
\hline Present & 4 & 14 & \\
\hline \multicolumn{4}{|l|}{ Renal comorbidity } \\
\hline Absent & 80 & 230 & \multirow[t]{2}{*}{$<0.001$} \\
\hline Present & 5 & 0 & \\
\hline \multicolumn{4}{|l|}{ Preoperative symptom } \\
\hline Absent & 49 & 118 & \multirow[t]{2}{*}{0.316} \\
\hline Present & 36 & 112 & \\
\hline $\begin{array}{l}\text { Preoperative body mass } \\
\text { index, mean } \pm \mathrm{SD}\end{array}$ & $22.2 \pm 3.1$ & $21.9 \pm 3.4$ & 0.340 \\
\hline \multicolumn{4}{|l|}{ Tumor location } \\
\hline Entire & 2 & 8 & \multirow[t]{4}{*}{0.586} \\
\hline Upper third & 21 & 49 & \\
\hline Middle third & 27 & 90 & \\
\hline Lower third & 35 & 83 & \\
\hline \multicolumn{4}{|l|}{ Tumor size (mm) } \\
\hline$<50$ & 45 & 129 & \multirow[t]{2}{*}{0.619} \\
\hline$\geq 50$ & 40 & 101 & \\
\hline \multicolumn{4}{|l|}{ UICC cT factor } \\
\hline $\mathrm{cT} 1$ & 0 & 0 & \multirow[t]{4}{*}{0.533} \\
\hline $\mathrm{cT} 2$ & 37 & 106 & \\
\hline cT3 & 26 & 78 & \\
\hline cT4 & 22 & 46 & \\
\hline \multicolumn{4}{|l|}{ UICC $\mathrm{cN}$ factor } \\
\hline $\mathrm{cNO}$ & 43 & 109 & \multirow[t]{4}{*}{0.820} \\
\hline $\mathrm{cN} 1$ & 25 & 67 & \\
\hline $\mathrm{cN} 2$ & 15 & 44 & \\
\hline $\mathrm{cN} 3$ & 2 & 10 & \\
\hline \multicolumn{4}{|l|}{ UICC clinical stage } \\
\hline IB & 24 & 67 & \multirow[t]{6}{*}{0.772} \\
\hline IIA & 23 & 51 & \\
\hline IIB & 14 & 54 & \\
\hline IIIA & 18 & 41 & \\
\hline IIIB & 4 & 12 & \\
\hline IIIC & 2 & 5 & \\
\hline
\end{tabular}

Table 2 continued

\begin{tabular}{llll}
\hline Variables & $\begin{array}{l}\text { eGFR }<63.2 \\
(n=85)\end{array}$ & $\begin{array}{l}\text { eGFR } \geq 63.2 \\
(n=230)\end{array}$ & $p$ value \\
\hline $\begin{array}{l}\text { Operative procedure } \\
\quad\end{array}$ & 29 & 87 & 0.543 \\
$\quad \begin{array}{l}\text { Total gastrectomy } \\
\text { Distal gastrectomy }\end{array}$ & 56 & 143 & \\
$\begin{array}{l}\text { Splenectomy } \\
\text { Absent }\end{array}$ & 68 & 175 & 0.458 \\
$\quad$ Present & 17 & 55 & 0.163 \\
$\begin{array}{l}\text { Dissected lymph nodes, } \\
\text { mean } \pm \text { SD }\end{array}$ & $36.5 \pm 16.4$ & $38.6 \pm 17.4$ & \\
$\begin{array}{l}\text { Operative time (min), } \\
\text { mean } \pm \text { SD }\end{array}$ & $252 \pm 93$ & $242 \pm 75$ & 0.572 \\
$\begin{array}{l}\text { Estimated blood loss } \\
\text { (ml), median (range) }\end{array}$ & $295(9-3698)$ & $263(1-4267)$ & 0.222 \\
$\begin{array}{l}\text { Postoperative } \\
\text { complication }\end{array}$ & & & \\
$\quad \begin{array}{l}\text { Absent } \\
\text { Present }\end{array}$ & 62 & 210 & $<0.001$ \\
\hline
\end{tabular}

$S D$ standard deviation, UICC Union for International Cancer Control dysfunction, and the other complications were $16(5.1 \%), 15$ (4.8\%), $10(3.2 \%), 3(1.0 \%), 2(0.6 \%)$, and $9(2.9 \%)$, respectively. Among them, incidence of anastomotic leakage was significantly associated with preoperative eGFR levels (Fig. 3a).

To further investigate the relationship between preoperative eGFR and postoperative complications, we performed a multivariate binomial logistic analysis involving other potential risk factors (only those determined before surgery), which showed that eGFR $<63.2$ was an independent risk factor for postoperative complications (odds ratio 4.67, $95 \%$ confidence interval $2.16-10.5, p<0.001$ ) (Table 3).

\section{Subgroup analyses}

We performed subgroup analyses to evaluate the clinical impact of preoperative eGFR on patient postoperative course. The 315 patients were subdivided according to age ( $<65$ or $\geq 65$ years), preoperative BMI ( $<22$ or $\geq 22$ ), operative procedure (total or partial gastrectomy), and clinical disease stage. Our results showed that patients with preoperative eGFR $<63.2$ experienced a higher incidence of postoperative complications in all subgroups (Fig. 3b), indicating that preoperative eGFR is applicable to various clinical settings.

\section{Discussion}

Our results support a significant relationship between preoperative eGFR and postoperative complications such as anastomotic leakage. eGFR had the highest AUC value 

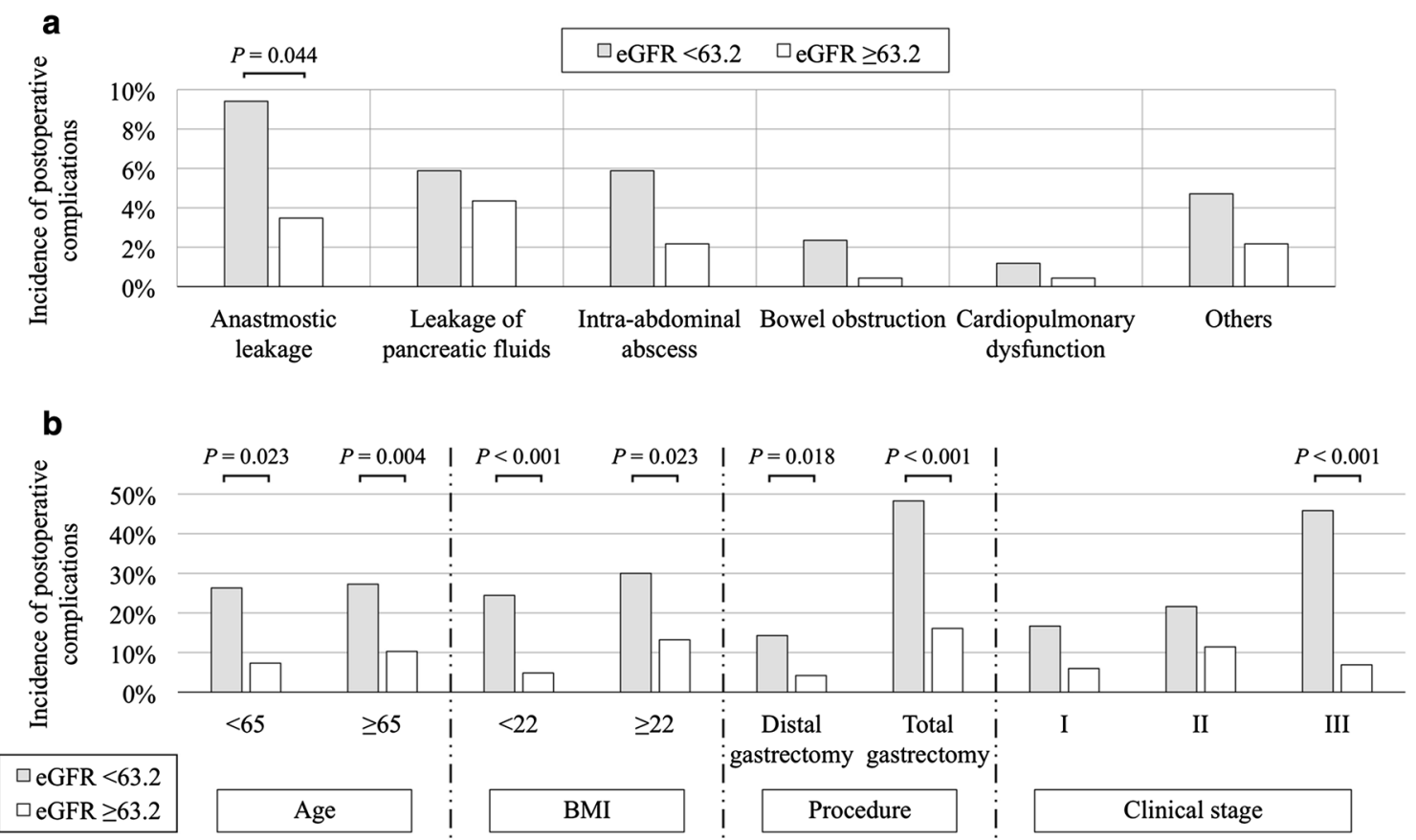

Fig. 3 a Incidence of each type of postoperative complication according to preoperative eGFR levels. b Subgroup analyses of the impact of eGFR on postoperative complications according to age, body mass index, operative procedure, and clinical disease stage

Table 3 Predictive factors for grade III or IV complications according to the Clavien-Dindo system; univariate and multivariable analyses

\begin{tabular}{|c|c|c|c|c|c|c|}
\hline \multirow[t]{2}{*}{ Variables } & \multicolumn{3}{|l|}{ Univariate } & \multicolumn{3}{|c|}{ Multivariable } \\
\hline & Odds ratio & $95 \% \mathrm{CI}$ & $p$ value & Odds ratio & $95 \% \mathrm{CI}$ & $p$ value \\
\hline Age ( $\geq 65$ years) & 1.84 & $0.95-3.73$ & 0.072 & 1.44 & $0.64-3.34$ & 0.379 \\
\hline Gender (male) & 2.95 & $1.22-8.80$ & 0.015 & 2.08 & $0.77-6.68$ & 0.158 \\
\hline Preoperative symptoms & 0.88 & $0.45-1.67$ & 0.692 & & & \\
\hline Diabetes mellitus & 1.78 & $0.71-4.02$ & 0.205 & & & \\
\hline Cardiac comorbidity & 1.78 & $0.90-3.45$ & 0.095 & 1.04 & $0.46-2.28$ & 0.931 \\
\hline Pulmonary comorbidity & 1.89 & $0.52-5.59$ & 0.308 & & & \\
\hline Preoperative symptoms & 0.85 & $0.44-1.63$ & 0.620 & & & \\
\hline Body mass index $(\geq 22)$ & 1.94 & $1.01-3.79$ & 0.046 & 2.49 & $1.16-5.55$ & 0.019 \\
\hline Preoperative eGFR $\left(<63.2 \mathrm{ml} / \mathrm{min} / 1.73 \mathrm{~m}^{2}\right)$ & 3.90 & $2.01-7.62$ & $<0.001$ & 4.67 & $2.16-10.5$ & $<0.001$ \\
\hline Tumor location (lower third) & 0.46 & $0.21-0.94$ & 0.033 & 0.94 & $0.35-2.53$ & 0.909 \\
\hline Macroscopic tumor size $(>50 \mathrm{~mm})$ & 1.50 & $0.79-2.88$ & 0.217 & & & \\
\hline UICC cT (cT4) & 1.12 & $0.43-2.01$ & 0.776 & & & \\
\hline $\mathrm{UICC} \mathrm{cN}(\mathrm{cN} 1-3)$ & 2.31 & $1.13-5.12$ & 0.021 & 2.93 & $1.32-7.08$ & 0.008 \\
\hline Planned operative procedure (total gastrectomy) & 4.40 & $2.25-8.98$ & $<0.001$ & 5.83 & $2.43-15.2$ & $<0.001$ \\
\hline
\end{tabular}

Analyses were performed using binomial logistic analysis

CI confidence interval, UICC Union for International Cancer Control

among the renal function-related indicators for the incidence of postoperative complications. Low preoperative eGFR was identified as an independent risk factor for postoperative complications in the multivariable analysis. Also, low preoperative eGFR was associated with a higher incidence of postoperative complications independent of age, BMI, operative procedure, and disease stage. Reflecting these findings, postoperative hospital stay was prolonged in the low preoperative eGFR group.

Preoperative eGFR is a simple potential prediction tool for complications after gastrectomy that can be added to the clinical judgment and experience of the surgeons for 
estimating the risk of adverse outcomes for GC patients. The use of this prediction tool could help in patient counseling and the informed consent process and can identify high-risk patients to tailor perioperative care and improve postoperative short-term outcomes [13, 24]. Our data also suggest that eGFR could become a potential constituent of integrated scoring systems for surgical risk assessment [24, 25].

Our results indicated the threshold level of preoperative eGFR that is associated with an incidence of postoperative complications. The eGFR cutoff value of $63.2 \mathrm{ml} / \mathrm{min} /$ $1.73 \mathrm{~m}^{2}$ is classified as stage $\mathrm{G} 2$, indicating individuals with normal or minimal chronic kidney damage, according to the Kidney Disease Improving Global Outcomes group guidelines [26]. Patients at stage G2 are considered nonchronic kidney disease patients unless continuous proteinuria is present [26]. Our results indicated that eGFR is a useful tool capable of determining patients at risk of postoperative complications even while they are asymptomatic and lacking clinical signs of renal dysfunction.

The association between eGFR and an underlying host characteristic that predisposes to postoperative complications in patients with GC remains unclear. A plausible explanation is that low eGFR may reflect compromised function in major organs that is associated with host vulnerability $[14,27]$. Even in patients with subtle disease, deterioration of drug metabolism/excretion and edema of the tissues resulting from water-electrolyte imbalance may result in poor wound healing, insufficient infection control, and, ultimately, the development of serious complications [28, 29]. Moreover, it has been reported that immune response deficiency is common in patients with chronic kidney diseases [30]. For example, functional competence of monocytes and macrophages is diminished in those patients despite elevated levels of cytokines [31, 32]. Contin et al. reported that high levels of serum-soluble CD40 correlate with elevated serum creatinine, suggesting humoral immune defense is also compromised [33]. Thus, humoral and cellular immune dysfunction might contribute to aggravation of postoperative complications in patients with low eGFR.

Our study has certain limitations, including that this was a retrospective study performed in a single institute involving data from a medical database from a limited number of patients. As we focused on D2 gastrectomy for advanced GC, the predictive value of eGFR in cT1 GC remains to be determined. Also, data on duration of drain placement and fasting, which might deepen discussion on the association between preoperative eGFR and deteriorated healing, were unavailable at the time of this study. Our findings require validation by further large-scale prospective studies.
In conclusion, our results indicated that preoperative eGFR is a useful predictor of complications after gastrectomy in patients with GC. Risk stratification according to preoperative eGFR can be used in the decision-making process before gastrectomy and may eventually improve clinical care, as well as the process of obtaining informed consent.

\section{Compliance with ethical standards}

Conflict of interest None declared.

Research involving human participants informed consent This study conforms to the ethical guidelines of the World Medical Association Declaration of Helsinki-Ethical Principles for Medical Research Involving Human Subjects, and written informed consent for surgery and the use of clinical data was obtained from all patients as required by the Institutional Review Board of Nagoya University.

\section{References}

1. Siegel RL, Miller KD, Jemal A. Cancer statistics, 2015. CA Cancer J Clin. 2015;65:5-29.

2. Kanda M, Murotani K, Kobayashi D, Tanaka C, Yamada S, Fujii $\mathrm{T}$, et al. Postoperative adjuvant chemotherapy with $\mathrm{S}-1$ alters recurrence patterns and prognostic factors among patients with stage II/III gastric cancer: a propensity score matching analysis. Surgery (St. Louis). 2015;158:1573-80.

3. Van Cutsem E, Sagaert X, Topal B, Haustermans K, Prenen H. Gastric cancer. Lancet. 2016;S0140-6736:30354-3.

4. Kanda M, Kobayashi D, Tanaka C, Iwata N, Yamada S, Fujii T, et al. Adverse prognostic impact of perioperative allogeneic transfusion on patients with stage II/III gastric cancer. Gastric Cancer. 2016;19:255-63.

5. Songun I, Putter H, Kranenbarg EM, Sasako M, van de Velde CJ. Surgical treatment of gastric cancer: 15 -year follow-up results of the randomised nationwide Dutch D1D2 trial. Lancet Oncol. 2010;11:439-49.

6. Jiang X, Hiki N, Nunobe S, Kumagai K, Nohara K, Sano T, et al. Postoperative pancreatic fistula and the risk factors of laparoscopy-assisted distal gastrectomy for early gastric cancer. Ann Surg Oncol. 2012;19:115-21.

7. Kanda M, Fujii T, Suenaga M, Takami H, Hattori M, Inokawa Y, et al. Estimated pancreatic parenchymal remnant volume accurately predicts clinically relevant pancreatic fistula after pancreatoduodenectomy. Surgery (St. Louis). 2014;156:601-10.

8. Fujii T, Kanda M, Nagai S, Suenaga M, Takami H, Yamada S, et al. Excess weight adversely influences treatment length of postoperative pancreatic fistula: a retrospective study of 900 patients. Pancreas. 2015;44:971-6.

9. Kubota T, Hiki N, Nunobe S, Kumagai K, Aikou S, Watanabe R, et al. Significance of the inflammation-based Glasgow prognostic score for short- and long-term outcomes after curative resection of gastric cancer. J Gastrointest Surg. 2012;16:2037-44.

10. Bartlett EK, Roses RE, Kelz RR, Drebin JA, Fraker DL, Karakousis GC. Morbidity and mortality after total gastrectomy for gastric malignancy using the American College of Surgeons National Surgical Quality Improvement Program database. Surgery (St. Louis). 2014;156:298-304.

11. Chen HN, Chen XZ, Zhang WH, Yang K, Chen XL, Zhang B, et al. The impact of body mass index on the surgical outcomes of 
patients with gastric cancer: a 10-year, single-institution cohort study. Medicine (Baltim). 2015;94:e1769.

12. Kanda M, Mizuno A, Tanaka C, Kobayashi D, Fujiwara M, Iwata $\mathrm{N}$, et al. Nutritional predictors for postoperative short-term and long-term outcomes of patients with gastric cancer. Medicine (Baltim). 2016;95:e3781.

13. Hong S, Wang S, Xu G, Liu J. Evaluation of the POSSUM, p-POSSUM, o-POSSUM, and APACHE II scoring systems in predicting postoperative mortality and morbidity in gastric cancer patients. Asian J Surg. 2015;S1015-9584:00089-5.

14. James MT, Hemmelgarn BR, Wiebe N, Pannu N, Manns BJ, Klarenbach SW, et al. Glomerular filtration rate, proteinuria, and the incidence and consequences of acute kidney injury: a cohort study. Lancet. 2010;376:2096-103.

15. Hayashi T, Aoyama T, Tanabe K, Nishikawa K, Ito Y, Ogata T, et al. Low creatinine clearance is a risk factor for D2 gastrectomy after neoadjuvant chemotherapy. Ann Surg Oncol. 2014;21:3015-22.

16. Kanda M, Mizuno A, Fujii T, Shimoyama Y, Yamada S, Tanaka $\mathrm{C}$, et al. Tumor infiltrative pattern predicts sites of recurrence after curative gastrectomy for stages 2 and 3 gastric cancer. Ann Surg Oncol. 2016;23:1934-40.

17. Japanese Gastric Cancer Association. Japanese classification of gastric carcinoma, 3rd English edition. Gastric Cancer. 2011;14:101-12.

18. Sobin LH, Gospodarowicz MK, Wittekind C. International Union Against Cancer: TNM classification of malignant tumors. 7th ed. New York: Wiley-Blackwell; 2009.

19. Kanda M, Fujiwara M, Tanaka C, Kobayashi D, Iwata N, Mizuno A, et al. Predictive value of drain amylase content for peripancreatic inflammatory fluid collections after laparoscopic (assisted) distal gastrectomy. Surg Endosc. 2016;30:4353-62.

20. Kanda M, Fujii T, Takami H, Suenaga M, Inokawa Y, Yamada S, et al. Novel diagnostics for aggravating pancreatic fistulas at the acute phase after pancreatectomy. World J Gastroenterol. 2014;20:8535-44.

21. Clavien PA, Barkun J, de Oliveira ML, Vauthey JN, Dindo D, Schulick RD, et al. The Clavien-Dindo classification of surgical complications: five-year experience. Ann Surg. 2009;250: 187-96.

22. Kanda M, Shimizu D, Tanaka H, Shibata M, Iwata N, Hayashi M, et al. Metastatic pathway-specific transcriptome analysis identifies MFSD4 as a putative tumor suppressor and biomarker for hepatic metastasis in patients with gastric cancer. Oncotarget. 2016;7:13667-79.
23. Kanda M, Shimizu D, Fujii T, Sueoka S, Tanaka Y, Ezaka K, et al. Function and diagnostic value of Anosmin-1 in gastric cancer progression. Int J Cancer. 2016;138:721-30.

24. Kurita N, Miyata H, Gotoh M, Shimada M, Imura S, Kimura W, et al. Risk model for distal gastrectomy when treating gastric cancer on the basis of data from 33,917 Japanese patients collected using a nationwide web-based data entry system. Ann Surg. 2015;262:295-303.

25. Watanabe M, Miyata H, Gotoh M, Baba H, Kimura W, Tomita N, et al. Total gastrectomy risk model: data from 20,011 Japanese patients in a nationwide internet-based database. Ann Surg. 2014;260:1034-9.

26. Inker LA, Astor BC, Fox CH, Isakova T, Lash JP, Peralta CA, et al. KDOQI US commentary on the 2012 KDIGO clinical practice guideline for the evaluation and management of CKD. Am J Kidney Dis. 2014;63:713-35.

27. Labaf A, Grzymala-Lubanski B, Sjalander A, Svensson PJ, Stagmo M. Glomerular filtration rate and association to stroke, major bleeding, and death in patients with mechanical heart valve prosthesis. Am Heart J. 2015;170:559-65.

28. Matsumoto S, Takayama T, Wakatsuki K, Tanaka T, Migita K, Nakajima Y. Short-term and long-term outcomes after gastrectomy for gastric cancer in patients with chronic kidney disease. World J Surg. 2014;38:1453-60.

29. Liu YY, Tsai CY, Yeh CN, Chiang KC, Wang SY, Cheng CT, et al. Gastric cancer patients with end-stage renal disease who underwent radical gastrectomy. Anticancer Res. 2015;35:2263-8.

30. Canedo J, Ricciardi K, DaSilva G, Rosen L, Weiss EG, Wexner SD. Are postoperative complications more common following colon and rectal surgery in patients with chronic kidney disease? Colorectal Dis. 2013;15:85-90.

31. Girndt M, Sester U, Kaul H, Kohler H. Production of proinflammatory and regulatory monokines in hemodialysis patients shown at a single-cell level. J Am Soc Nephrol. 1998;9:1689-96.

32. Ruiz P, Gomez F, Schreiber AD. Impaired function of macrophage Fc gamma receptors in end-stage renal disease. $\mathrm{N}$ Engl $\mathrm{J}$ Med. 1990;322:717-22.

33. Contin C, Pitard V, Delmas Y, Pelletier N, Defrance T, Moreau $\mathrm{JF}$, et al. Potential role of soluble CD40 in the humoral immune response impairment of uraemic patients. Immunology. 2003;110:131-40. 